\title{
INTRODUCTION
}

\section{INTRODUCTION TO THE SPECIAL ISSUE: YOUTH MENTORING: BRIDGING SCIENCE WITH PRACTICE}

David L. DuBois

University of Illinois at Chicago

Jean E. Rhodes

University of Massachusetts, Boston

\begin{abstract}
Initiatives to promote mentoring relationships in the lives of young people have become immensely popular in recent years. Programs with this aim now number well into the thousands and benefit from significant levels of governmental, corporate, and philanthropic support. The research base that is necessary to inform the practice of mentoring, by comparison, has lagged behind. To address the field's need for a stronger scientific foundation, MENTOR/National Mentoring Partnership convened the National Research Summit on Mentoring in 2003. A policy brief that resulted from the summit identified several priority areas for future research on youth mentoring, as well as strategic mechanisms to support this work. This special issue features reports from working groups at the summit that were organized around the following themes: evaluation and research methodology, relationships, programs, contexts, special populations, developmental and cultural perspectives, and community organizing and advocacy. Collectively, the reports highlight the need for research to clarify a wide range of important theoretical and pragmatic issues in efforts to promote effective mentoring of youth. (c) 2006 Wiley Periodicals, Inc.
\end{abstract}

Initiatives to promote mentoring relationships in the lives of young people have become immensely popular in recent years. Programs with this aim now number well into the thousands and benefit from significant levels of governmental, corporate, and philanthropic

The authors gratefully acknowledge the leadership of MENTOR/National Mentoring Partnership in organizing and convening the National Research Summit on Mentoring that is described in this article, as well as the funding received from the Kauffman Foundation, the William T. Grant Foundation, and the MacArthur Research Network on Transitions to Adulthood.

Correspondence to: David L. DuBois, Institute for Health Research and Policy, University of Illinois at Chicago, 1747 W. Roosevelt Rd., Chicago, IL 60608. E-mail: dldubois@uic.edu

JOURNAL OF COMMUNITY PSYCHOLOGY, Vol. 34, No. 6, 647-655 (2006)

Published online in Wiley InterScience (www.interscience.wiley.com).

(c) 2006 Wiley Periodicals, Inc. DOI: 10.1002/jcop.20121 
support (DuBois \& Karcher, 2005b). The unprecedented growth in structured mentoring programs, such as Big Brothers Big Sisters, has been coupled with increased recognition of the significance of relationships between adults and young people across a broad range of youth-serving organizations and institutions (Zeldin, Larson, \& Camino, 2005), as well as those that can develop more informally in extended families, neighborhoods, and communities (Scales, 2003).

This surge of interest in mentoring undoubtedly owes some measure of debt to an array of research findings over the past several decades that have highlighted positive contributions nonparental adults can make in the lives of youth (Baker \& McGuire, 2005). Noteworthy among these are studies in the resiliency literature that pointed to close relationships with nonparental adults as a protective factor (Werner, 1995), those documenting favorable outcomes for youth participating in prevention programs in which nonprofessionals or paraprofessionals were relied on as the primary agents of intervention (Orford, 1992), and Public/Private Ventures' (PPV's) landmark evaluation of the Big Brothers/Big Sisters program (Tierney, Grossman, \& Resch, 1995), the findings of which were widely heralded as a convincing demonstration of the benefits of program-initiated mentoring relationships for youth (Walker, 2005). All told, this research offered a secure platform from which to launch intensified efforts to sponsor mentoring initiatives at local, state, and national levels during the past decade.

As research and practice have continued to evolve, however, a number of important theoretical and pragmatic issues that require clarification through an empirical lens have moved to the forefront. Several developments have been instrumental in this regard. First, rigorous analysis of the extant research on the effectiveness of mentoring programs has revealed considerable room for improvement in both the strength and consistency of their impacts on youth (for reviews, see DuBois, Holloway, Valentine, \& Cooper, 2002; Rhodes, 2002). In their metaanalysis of 55 evaluations of youth mentoring programs, DuBois and associates (2002) found evidence of only a small benefit, on average, for participating youth on measures of emotional, behavioral, and educational functioning (Cohen's $d=.14$ ). Importantly, effect-size estimates varied considerably and were found to increase systematically in conjunction with the use of a variety of program practices (DuBois et al., 2002). The authors emphasized that these and other practices merited further examination in more rigorously controlled experimental studies. Several investigations also have highlighted the importance of other program and relationship characteristics. Analyzing data from the national Big Brothers Big Sisters study, Grossman and Rhodes (2002) found that the effects of mentor relationships varied with their duration. Youth who were in matches that terminated within the first 3 months experienced significantly larger drops in feelings of self-worth and lower perceived scholastic competence than youth who did not receive any mentoring at all. On the other hand, youth who were in matches that lasted more than 12 months reported significantly higher levels of self-worth, social acceptance, and scholastic competence than the control subjects. Such trends may account, in part, for the finding that benefits of participation in the Big Brothers/Big Sisters program derived from results of the same evaluation were estimated to exceed costs by only a narrow margin (estimate of $\$ 1.01$ benefit for each $\$ 1.00$ of cost when including both taxpayer and other costs; see Aos, Lieb, Mayfield, Miller, \& Pennucci, 2004). Collectively, these types of findings underscore the need for greater empirical delineation of the conditions under which mentoring programs can more fully realize their promise of having a positive and transformative impact on young people's lives (DuBois \& Karcher, 2005b).

A second development has been the rapid emergence of new models of practice and their application to an increasingly wide range of youth populations. Existing research per- 
tains predominantly to a traditional model of mentoring embodied by programs such as Big Brothers Big Sisters. In this model, mentors and youth are paired through a formal mechanism; mentors and youth interact with each other in person and on a one-on-one basis; the mentor is an adult volunteer; and mentors and youth are largely free to spend time together in a range of different activities and settings. Recent years have witnessed increasingly widespread implementation of alternative approaches to youth mentoring that represent significant departures from each of the major dimensions of this model. These include, but are not limited to, approaches that are geared toward encouraging mentoring relationships through more informal and indirect mechanisms, such as improvements in youth-serving organizations, school reform, and community capacity building; group mentoring; e-mentoring programs in which mentors and youth communicate over the Internet; peer mentoring programs in which older youth are utilized as mentors; and site-based models in which interactions between youth and mentors are limited to a particular setting, such as school, the workplace, or an after-school program. Indeed, recent estimates indicate that programs that employ a community-based model are now only slightly more common $(54 \%)$ than those in which mentoring activities are site based (Manza, 2003).

Paralleling these trends in the structure and design of program, there have been numerous initiatives to tailor mentoring programs to serve the needs of particular populations of youth better. These populations include, but again are not limited to, youth in foster care, academically at-risk students, youth who have a parent who is incarcerated, youth involved in the juvenile justice system, youth who have disabilities, and pregnant and parenting adolescents. To date, very little research has been conducted either to inform these newer approaches to youth mentoring or to evaluate their effectiveness. Reflecting this state of affairs, the editors of the recently published Handbook of Youth Mentoring (DuBois \& Karcher, 2005a) concluded that even when applying a liberal criterion, insufficient scholarship existed to merit the inclusion of chapters on some of the newest modalities of mentoring (e.g., group mentoring) or the mentoring of various specialized populations (e.g., youth who have incarcerated parents). As the practice of youth mentoring continues to evolve, it will become increasingly critical to address the gaps that are evident between these developments and a knowledge base that was created primarily from a traditional and largely nonspecific model of programmatic mentoring.

A final important trend is a relative lack of dedicated funding for research on youth mentoring. Investigations of mentoring have been supported primarily on an ad hoc basis through general-purpose funding mechanisms of governmental agencies and private foundations. Most funding for youth mentoring has been directed to expanding the practice base of the field rather than conducting programmatic research or rigorous evaluation. Clearly, without a balanced investment in both the practice and the science of mentoring, the gap between them can be expected only to widen over time (DuBois \& Karcher, 2005b).

\section{NATIONAL RESEARCH SUMMIT ON MENTORING}

To address the need for a stronger scientific foundation in practices to promote effective youth mentoring, MENTOR/National Mentoring Partnership, a leading policy and advocacy organization in the field, convened the National Research Summit on Mentoring in 2003 in Kansas City, Missouri. The summit was cochaired by the editors of this volume and was supported by funding from the Kauffman Foundation, the William T. Grant Foundation, and the MacArthur Research Network on Transitions to Adulthood. Summit 
participants included 27 scholars who were recognized as having made significant contributions to understanding of issues involved with youth mentoring in each of several key areas: evaluation and research methodology, programs, relationships, contexts, special populations, developmental and cultural perspectives, and community organizing and advocacy. Several graduate students and postdoctoral fellows who were currently participating in the research programs of the invited scholars also attended. After a series of presentations from the keynote speakers and each of the participating scholars, summit participants worked in teams to review critically and integrate available research pertaining to each of the topic areas.

After the summit, a policy brief was published by MENTOR/National Mentoring Partnership, National Research Agenda for Youth Mentoring (Rhodes \& DuBois, 2004). The Agenda highlighted several priority areas for strengthening the field's knowledge base, as well as recommended strategies to ensure balanced and comprehensive support of research in these areas (for a summary, see Table 1). Through the efforts of MENTOR/National Mentoring Partnership, the brief was disseminated to more than 10,000 practitioners, policy makers (including members of Congress), and funders.

\section{THIS SPECIAL ISSUE}

This special issue features articles by scholars from each of the working groups referred to previously, as well as from one of the summit's keynote presenters (Reed Larson). Each article features a review of relevant theoretical and empirical literatures and a set of recommendations for future research.

DuBois and colleagues in their report underscore that the mentoring of young people is an inherently complex phenomenon with a range of significant processes that occur at the levels of individual youth and their mentors, youth-mentor relationships and other interpersonal systems, programs, and the larger policy context and that evaluation and research methods thus need to be well suited to capturing this complexity. These authors argue, furthermore, that programs of research that progress systematically through the major recommended phases of the intervention research cycle from the broader field of prevention science (i.e., preintervention, intervention, and preventive service systems research) are needed. Their analysis reveals significant gaps in the types of research that have been conducted relevant to the goals of each of these phases, as well as a variety of methodological concerns pertaining to sampling, design, assessment, and data analysis that merit attention in future work. Equally important, this working group's report concludes that needed linkages across different phases of intervention research are lacking. They point out, for example, that mentoring programs for youth often have not benefited from formative, preintervention research before being subjected to evaluation and or have simply proceeded to large-scale dissemination, bypassing controlled evaluation trials altogether. Throughout their report, DuBois and colleagues emphasize the need for stronger collaboration between researchers and those in practice and policy settings and discuss the ways in which such collaboration could enhance both the impact and the reach of mentoring programs for youth.

Two articles by Larson and by Rhodes and colleagues then address mentoring relationships and our current understanding of the processes and dynamics that may be most influential in determining their effectiveness. Larson argues for viewing mentoring relationships within a framework of positive youth development that emphasizes young people's capacity for being motivated by challenge. Larson considers ways in which caring 
Table 1. Summary of National Research Agenda for Youth Mentoring

\begin{tabular}{l} 
Priority areas for future research \\
\hline Evaluating the new generation of programs \\
Alternatives to the traditional mentoring program model \\
such as group, peer, and e-mentoring, as well as strategies \\
tied to particular types of settings-such as school-, work- \\
place-, and faith-based mentoring-are experiencing rapid \\
growth but have been subjected to very little rigorous investi- \\
gation. Mentoring researchers need (1) to gauge both the \\
effectiveness and costs of newer approaches to mentoring \\
carefully, using randomized, controlled studies and (2) to \\
translate findings into practical decision-making guidelines \\
for program developers and funding agencies.
\end{tabular}

\section{Deciphering "best practices" in mentoring}

Researchers need to evaluate mentoring program practices carefully for their ability to facilitate enduring, positive outcomes for youth. Systematic comparison of practices of differing type and intensity is needed within all relevant program areas, including recruitment, training, matching, supervision, and mentor/mentee activities. Researchers need to make these comparisons within specific program models (for example, group mentoring), as well as across the entire spectrum of mentoring program models (for example, traditional one-to-one, group, peer, and e-mentoring).

\section{Integrating mentoring with other programs and services}

Mentoring is often included as part of a larger youth development program that has several different components. Currently, however, there is only limited understanding of how best to integrate mentoring with other types of services. Researchers need (1) to examine the extent to which mentoring adds to the effectiveness of programs with multiple components and (2) to evaluate strategies that may help to maximize these benefits.

\section{Understanding the link between mentoring and academic achievement}

Mentoring programs frequently are advocated as a means of promoting the academic achievement of children and adolescents who may be at risk for school failure. Researchers need to systematically investigate which types of programs and relationships are most effective for ensuring that youth benefit in this area.

\section{Improving mentor recruitment, training, and retention}

Most mentoring programs struggle to recruit adequate numbers of mentors to meet community needs. Furthermore, as many as half of volunteer mentor relationships dissolve after only a few months. Others fail to provide youth with the most needed forms of guidance and support. To inform efforts to address concerns in this area, researchers need to use rigorous methods to evaluate strategies for recruiting, training, and retaining mentors. The strategies examined should include both currently recommended approaches as detailed in resources such as the Elements of Effective Practice (MENTOR/National Mentoring Practice, 2003), as well as more recent, emerging innovations in practice.
Recommendations for

advancing research on mentoring

Increase support for youth

mentoring research through dedicated funding streams

Both government and private-sector organizations should dedicate streams of funding to mentoring research. Funding should be balanced across the full range of identified priority areas for investigation and should be focused on research that meets the highest standards of independent scientific peer review.

\section{Develop a standardized system for tracking and evaluating mentoring programs}

Youth mentoring programs urgently need a scientifically sound, standardized system of tools and technical assistance they can use to track their program data and evaluate their efforts. This standardized system should include a mechanism that allows for aggregation and analysis of data across programs and over time. Researchers could use the resulting data to investigate mentoring practices and procedureswhat works best, for whom, and under what circumstances, to examine how use of a tracking and evaluation system may influence program effectiveness and sustainability, and to illuminate regional and national trends in mentoring.

\section{Conduct a national longitudinal} study of youth mentoring

The federal government, private funding organizations, corporations, or a consortium of those groups should commission a major longitudinal study of mentoring relationships, using a large nationally representative sample of youth. This type of investigation would represent a landmark in efforts to understand mentoring relationships and their influence on youth outcomes and provide a unique opportunity to gain insight into the characteristics and benefits of mentoring relationships among specialized populations and groups of youth. (continued) 
Table 1.Contined

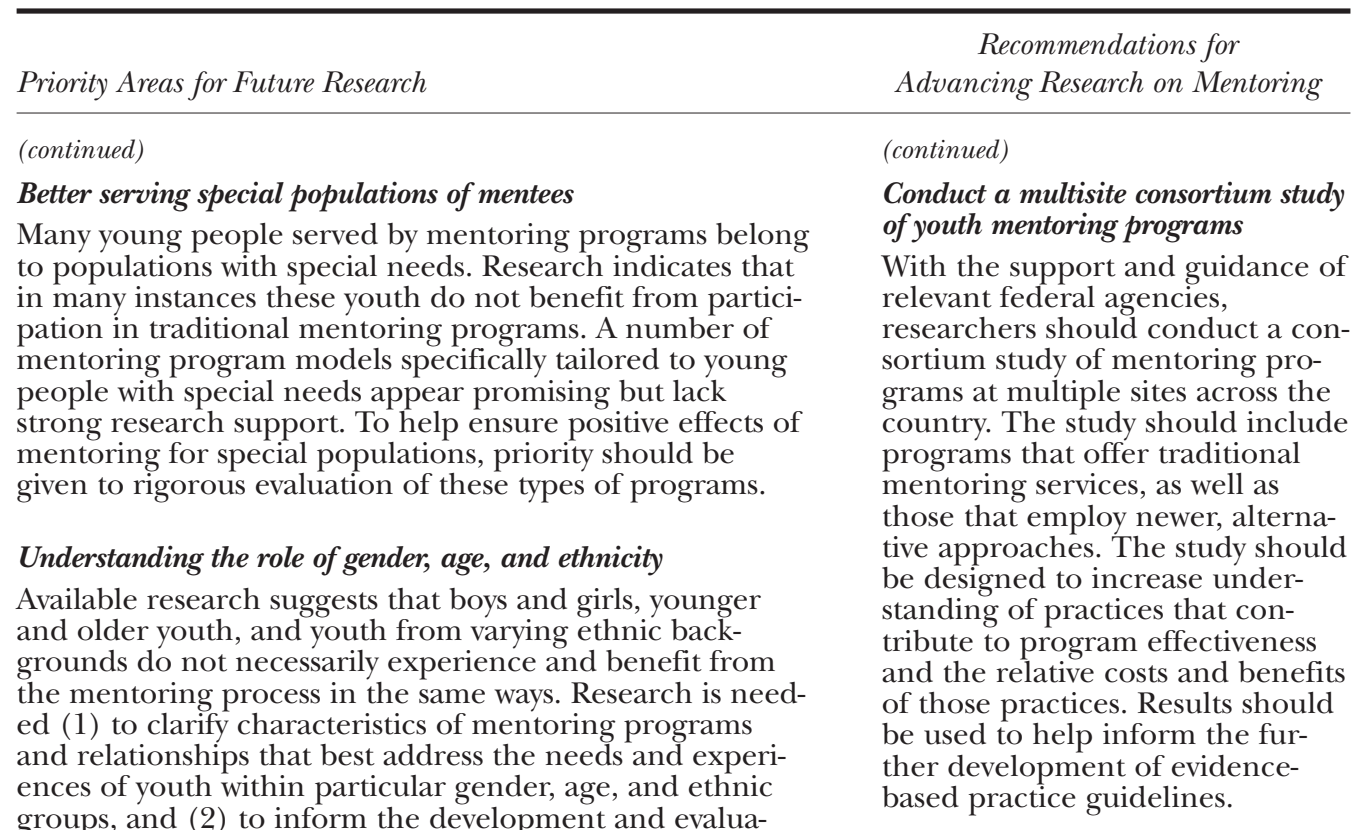
tion of approaches to mentoring that are tailored to the needs and preferences of youth who differ in gender, age, and ethnic background.

Understanding how mentoring relationships "work"

The relationship between a caring adult and a young person is at the heart of mentoring. Theoretical models that draw on related research show promise for informing understanding of how relationships actually influence youth outcomes but have not yet been rigorously evaluated. Research is needed to examine these processes more thoroughly, thereby helping mentoring programs develop more effective strategies for training and supervising mentors and for supporting and cultivating mentoring relationships. Research should investigate relationship processes from both the mentors' and mentees' perspectives and should attend carefully to patterns of stability and change in relationships over time, including the effect of the duration of a relationship on outcome.

\section{Linking research and practice}

Practice and policy decisions in the field of mentoring require a strong foundation in research. To facilitate this type of linkage, one priority should be the investigation of strategies that promote more widespread use of evidencebased practices, such as those detailed in the Elements of Effective Practice (MENTOR/National Mentoring Partnership, 2003). An equally important priority should be the development of research-based tools that can be used by organizations to evaluate and improve their mentoring programs. Research should examine what will induce organizations to use such tools and what effects their adoption may have on both program effectiveness and the entire mentoring field. 
adults, including mentors, can activate this motivation and thus support a process of positive development. A key theme throughout Larson's discussion is the need for adults to find ways to provide needed structure and guidance while supporting youth's development as agents of their own growth. He emphasizes the need for investigation and theory building that focus on the day-to-day processes and dynamics of mentoring relationships and on the ways in which these processes and their developmental implications may vary as a function of individual, situational, and cultural differences.

Rhodes and colleagues describe a model for the influence of mentoring relationships on youth development. This model posits that mentoring can affect youth through its impact on a range of interacting processes of social, emotional, cognitive, and identity development. As does Larson, they assume that a variety of contextual factors may be critically important in governing the strength and direction of the implications that these processes have for young people's development. These include, perhaps most notably, the quality and longevity of the mentoring relationship but also factors external to the relationship, such as the youth's history of previous attachments. Rhodes and colleagues review the ways in which existing research lends preliminary support to several aspects of their proposed model. They emphasize, however, that future research will need to devote much greater attention to understanding relationship processes if mentoring programs are to be effective in addressing the needs of the youth they serve.

In their article, Karcher and colleagues review what is currently known about the effectiveness of different types of programmatic approaches to youth mentoring. They propose a framework to guide future research in which program effectiveness is understood to be potentially influenced not only by distinctive features of the context, structure, and goals of programs, but also equally, or to an even greater extent, by program infrastructure and dosage. The authors recommend that rigorously designed evaluations be conducted to clarify the impact of approaches that differ along these dimensions and to test hypotheses regarding the influence of specific program elements.

Hamilton and colleagues focus on mentoring of young people that occurs naturally in different community contexts. Using an ecological perspective, they examine extant research on mentoring in four contexts: classrooms, youth development organizations, work and service-learning, and faith-based organizations. As the authors note, there has been only limited investigation of mentoring in these contexts. Hamilton and colleagues conclude, however, that available evidence indicates such mentoring can promote youths' social, psychological/emotional, and intellectual development. They highlight the need for future research to clarify the prevalence of naturally occurring mentoring in different community contexts, the circumstances in which it arises, its risks and benefits in different contexts, and interactive influences involving mentoring across multiple contexts and the features of supports and resources within the surrounding community. It is recommended that diverse research methods and designs be utilized to address these issues. One intriguing idea raised by the authors in this regard is the desirability of developing and evaluating interventions that seek to augment otherwise natural processes through which adults and youth become involved in mentoring in different community settings.

Britner and colleagues focus on the issues involved in mentoring populations of youth who have distinctive characteristics and needs. The authors discuss the potential relevance of several theoretical perspectives as frameworks for investigating unique facets and challenges of mentoring special populations of youth. They also critically review the limited extant research pertinent to the mentoring of five of the most salient of these populations: abused and neglected youth, youth who have disabilities, pregnant and parenting adolescents, juvenile offenders, and academically at-risk students. Their recom- 
mendations for future research highlight the need for careful attention to potential unintended negative effects of mentoring interventions for vulnerable populations of young people, methodological approaches that are sensitive to significant patterns of cooccurrence among risk factors, population membership and interventions for such populations, and the development and evaluation of mentoring practices that are geared specifically to the challenges presented by different vulnerable populations.

In a complementary article, Darling and colleagues focus on the implications of individual differences pertaining to the gender, ethnicity, and age of youth who participate in mentoring relationships and programs. The literatures addressing the influence of gender, ethnicity, and age on mentoring are reviewed and considered as exemplars of how mentoring programs may have different influences on, and outcomes for, specific groups of youth. Darling and colleagues emphasize that a major challenge for future research will be not only to articulate more clearly the separate influences of gender, ethnicity, and developmental level on mentoring processes and outcomes, but also to examine the complex implications of belonging to multiple subgroups.

Finally, Wandersman and colleagues focus on processes at the community level that may influence both the quantity and quality of mentoring programs for youth. After providing background on current funding initiatives in mentoring at the federal, state, and local levels, the authors discuss ways in which community organizing and advocacy involving multiple stakeholder groups may influence the demand for, and availability of, mentoring programs. Importantly, they also propose a model in which the organizational capacity of individual organizations or coalitions, in combination with training and technical assistance resources, influences the quality and effectiveness of mentoring programs in a community through intermediary effects on the use of evidence-based accountability principles in program implementation and evaluation. Wandersman and colleagues propose that future research use both correlational and experimental methods to begin to examine the ways in which the processes they describe may influence the effectiveness, reach, and sustainability of the structured mentoring opportunities that are available for youth within communities.

Collectively, the articles in this special issue highlight the need to clarify a wide range of issues important for understanding and promoting effective mentoring of youth. The directions for future research that are delineated offer valuable depth and detail to the priority areas outlined in National Research Agenda for Youth Mentoring. Equally important, they have the potential to prove advantageous as a foundation from which to engage in efforts to secure the resources necessary to implement the Agenda's recommended research strategies. It is thus from both a scholarly and a pragmatic perspective that we are hopeful this special issue will serve to help build stronger bridges among science, policy, and practice in youth mentoring.

\section{REFERENCES}

Aos, S., Lieb, R., Mayfield, J., Miller, M., \& Pennucci, A. (2004). Benefits and costs of prevention and early intervention programs for youth. Report to the Washington State Legislature. Olympia: Washington State Institute for Public Policy. Retrieved April 18, 2005, from http://www.wsipp.wa.gov/

Baker, D.B., \& Maguire, C.P. (2005). Mentoring in historical perspective. In D.L. DuBois \& M.J. Karcher (Eds.), Handbook of youth mentoring (pp. 14-29). Thousand Oaks, CA: Sage.

DuBois, D.L., Holloway, B.E., Valentine, J.C., \& Cooper, H. (2002). Effectiveness of mentoring programs for youth: A meta-analytic review. American Journal of Community Psychology, 30, 157-197. 
DuBois, D.L., \& Karcher, M.J. (2005a). Preface. In D.L. DuBois \& M.J. Karcher (Eds.), Handbook of youth mentoring (pp. xi-xii). Thousand Oaks, CA: Sage.

DuBois, D.L., \& Karcher, M.J. (2005b). Youth mentoring: Theory, research, and practice. In D.L. DuBois \& M.J. Karcher (Eds.), Handbook of youth mentoring (pp. 2-11). Thousand Oaks, CA: Sage.

Grossman, J.B., \& Rhodes, J.E. (2002). The test of time: Predictors and effects of duration in youth mentoring programs. American Journal of Community Psychology, 30, 199-219.

Manza, G. (2003, October). The state of mentoring 2003. Paper presented at 2003 National Research Summit on Mentoring, Kansas City, MO.

MENTOR/National Mentoring Partnership. (2003). Elements of effective practice (2nd ed.). Alexandria, VA: Author.

Orford, J. (1992). Community psychology: Theory and practice. Chichester, England: Wiley.

Rhodes, J.E. (2002). Stand by me: The risks and rewards of mentoring today's youth. Cambridge, MA: Harvard University Press.

Rhodes, J.E., \& DuBois, D. (2004). National research agenda for youth mentoring. Alexandria, VA: MENTOR/National Mentoring Partnership. Retrieved April 24, 2005, from http:// www.mentoring.org/program_staff/researchagenda.pdf

Scales, P.C. (2003). Other people's kids: Social expectations and American adults' involvement with children and adolescents. New York: Kluwer Academic/Plenum.

Tierney, J.P., Grossman, J.B., \& Resch, N.L. (1995). Making a difference: An impact study of Big Brothers/Big Sisters. Philadelphia: Public/Private Ventures.

Walker, G. (2005). Youth mentoring and public policy. In D.L. DuBois \& M.J. Karcher (Eds.), Handbook of youth mentoring (pp. 510-524). Thousand Oaks, CA: Sage.

Werner, E.E. (1995). Resilience in development. Current Directions in Psychological Science, 4, 81-85.

Zeldin, S., Larson, R., \& Camino, L. (Eds.). (2005). Youth-adult relationships in community programs: Diverse perspectives on good practices [special issue]. Journal of Community Psychology, 33(1), 1-138.

Journal of Community Psychology DOI: 10.1002/jcop 